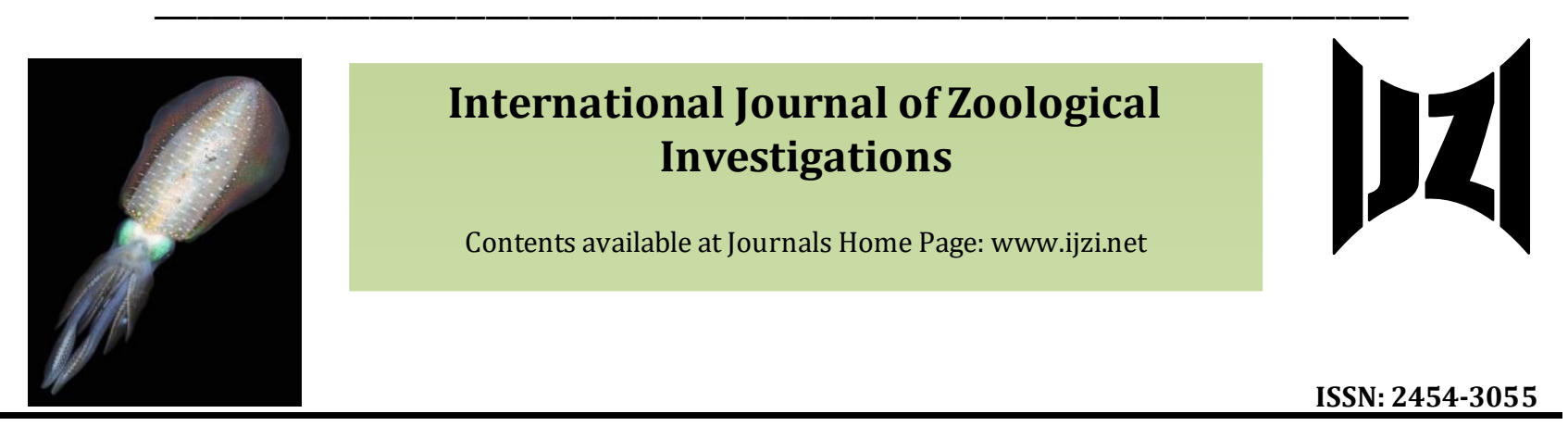

\title{
Assessment of Marine Debris and Plastic Polymer Types Along the Panvel Creek, Navi Mumbai, West Coast of India
}

\author{
Naik Mayur S., Supnekar Santosh P. and Pawar Prabhakar R.* \\ Mahatma Phule Arts, Science and Commerce College, Panvel, Raigad, Navi Mumbai - 410206, India \\ ${ }^{*}$ Corresponding Author
}

Received: 20th May, 2021

Accepted: 4th June, 2021

Published online: $5^{\text {th }}$ June, 2021

https://doi.org/10.33745/ijzi.2021.v07i01.023

\begin{abstract}
Marine debris was collected monthly from substations along Panvel creek from May 2020 to April 2021 and was analyzed for types of non-plastic debris and plastic debris. Plastic debris was assessed for \% composition of a type of plastic, plastic polymer and further categorized according to plastic code, acronym, full name and common examples. Non-plastic debris of 8 types representing 38 items were recorded. Consumer and manufactured items like glass and plastic bottles, cans, bags, rubber, metal, fiberglass, cigarettes, fishing gears etc. were observed. 8 types of polymers representing 65 items were recorded along Panvel creek. Plastic polymers like Polyethylene terephthalate (PETE/PET), High density polyethylene (HDPE), Polyvinyl chloride (PVC), Low density polyethylene (LDPE), Polypropylene (PE), Polystyrene (PS), Polyamide/Nylon, Acrylonitrile Butadiene Styrene (ABS) and Polyurethane (PU) were recorded. 13 items belongs to Plastic code 2:HDPE, 12 to 3:PVC, 11 to 5:PP, 9 to 6:PS, 8 to 4:LDPE, 6 to 1:PETE/PET and 3 each to 7:PA and Other and 8:PU, respectively, were documented. Maximum \% composition (20.00\%) of HDPE, and minimum (4.61\%) of PA and Other and PU, respectively was recorded. Higher content of debris recorded is attributed to the disposal of domestic wastes intentionally or unintentionally into the creek and also for disposal of scrap materials from the fishing crafts. Higher HDPE content is attributed to the wastes released from the fishing vessels and also to the domestic and municipal wastes. At present the Panvel creek is moderately polluted and 3R i.e. reduce, reuse and recycling is the current solution to the overuse of plastics.
\end{abstract}

Keywords: Domestic waste, Marine debris, Panvel creek, Plastic pollution, Polymer

Citation: Naik Mayur S., Supnekar Santosh P. and Pawar Prabhakar R.: Assessment of marine debris and plastic polymer types along the Panvel Creek, Navi Mumbai, West Coast of India. Intern. J. Zool. Invest. 7(1): 278-293, 2021. https://doi.org/10.33745/ijzi.2021.v07i01.023

\section{Introduction}

Any persistent solid material that is indirectly, intentionally or unintentionally manufactured or processed and directly or disposed off or abandoned into the marine 
environment is referred to as marine debris (NOAA, 2010; Brander et al., 2011; Kripa et al., 2016; Kaladharan et al., 2017).

Increasing urbanization of coastal settlements as well as tourism development has resulted in unprecedented production of anthropogenic waste (Kaladharan et al., 2017). Allsopp et al. (2009) reported that approximately $80 \%$ of debris originates onshore and 20\% from offshore sources (Moora and Piirsalu, 2016; Pawar et al, 2016). Marine debris is one of the most pervasive pollution affecting the world's oceans, coastal ecosystems and rivers (Sreelakshmi and Chitra, 2021). It has affected the ecosystem and livelihood of fishers. Indiscriminate dumping of solid waste on land reaches the drains, rivers and estuaries and finally ends up in the sea (Kripa et al., 2016).

Marine debris is a key environmental issue at the global level and a major threat to marine and coastal biodiversity. It is an urgent need to address marine debris as a global priority in recent years (CBD Technical Series No. 83, 2016). Ryan (2015) stated that a major threat to oceanic environment is accumulation of marine debris in water column, which is the result of decades of litter entering marine waters. According to Mugilarasan et al. (2017), marine debris from natural and anthropogenic sources has increased substantially.

Marine debris in the ocean is an emerging global environmental concern and increasing marine debris all along the coasts. It has been found in the pelagic environment worldwide and their quantity is increasing at an alarming rate, posing many threats to the coastal and marine environment (Maharana et al., 2019; Nisanth and Kumar, 2019). Over the past five or six decades, contamination and pollution of the world's enclosed seas, coastal waters and the wider open oceans by marine debris has been an ever-increasing phenomenon. The sources of the marine debris are both landand marine-based, their origins may be local or distant, and the environmental consequences are many and varied (Gregory, 2009).

Pawar et al. (2016) stated that marine debris is a globally recognized environmental issue of increasing concern. It includes consumer items such as glass or plastic bottles, cans, bags, balloons, rubber, metal, fiber glass, cigarettes, and other manufactured materials that end up in the ocean and along the coast. It also includes fishing gear such as line, ropes, hooks, buoys and other materials lost on or near land, or intentionally or unintentionally discarded at sea (Schwarz et al., 2019). Oceans provide many ecosystem services like provision of livelihoods, food, recreation and socio-cultural well-being, depend on healthy and resilient marine ecosystems. Many persistent drivers like marine debris are negatively impacting marine ecosystems and undermining their ability to continue to provide these services (CBD Technical Series No. 83, 2016).

Marine debris is recognized as a globally significant stressor on the marine and coastal environment, with impacts on marine biodiversity (Sridhar et al., 2007; Li et al., 2016). Marine debris from land-based and sea-based sources has tangible and widereaching impacts, affecting marine areas all over the world. The urgent need to address marine debris has emerged as a global priority in recent years (Worm et al., 2017). Kripa et al. (2016) noted that as per the UNEP guidelines for assessing debris, its materials 
are listed in seven types such as plastics, foamed plastics, cloth, glass and ceramics, metal, rubber, wood and others (electronic items, paraffin wax, etc.) (Sulochanan et al., 2013).

Barnes et al. (2009) stated that plastic accounts for $10 \%$ of all waste generated, with global use exceeding 260 million tons per annum. Due to its light weight and durable nature, plastics has become a prevalent, widespread element of marine debris (Thompson et al., 2009). Inadequate and overwhelmed waste management systems, open dumping, storms, and rain cause landbased sources of pollution to leak into rivers, coastal areas and oceans (Kapinga and Chung, 2020).

GESAMP (2015) reported that marine debris is a mixture of organic and inorganic matter where plastic particles dominate. Around $90 \%$ of all marine debris is composed of plastics and styrofoam, with food and beverage packaging being one of the most widespread items found on beaches around the world (Dharmamony, 2018). Plastic has been identified as a widespread and recalcitrant pollutant in aquatic environments and is now found in all major oceanic gyres, polar seas and deep sea sediments (Jambeck et al., 2015; Lusher et al., 2015; Erni-Cassola et al., 2019).

Plastics are synthetic organic polymers made by polymerizing molecules of monomer, materials that are derived from coal, petroleum or natural gas (Selukar et al., 2014; Pawar et al, 2016; Chatterjee and Sharma, 2019; Kumar et al., 2020). Plastic is costeffective, require little energy to produce, lightweight and biocompatible. It is soft, transparent, flexible, or biodegradable and used in engineered tissues, absorbable sutures, prosthetics, and other medical applications (Andrady and Neal, 2009). Plastics are used in food and product packaging, clothing, construction and car materials, household goods, medical devices, personal care products, toys, water bottles, clothing, medical supplies and electronic goods (Ghosh et al., 2013; Dharmamony, 2018; Alabi et al., 2019; Wang et al., 2020). Plastics are toxic substances that may leak out and adversely affect humans and other organisms (Proshad et al., 2018).

Worldwide polymer production was estimated to be 260 million metric tons per annum in the year 2007 for polymers like thermoplastics, thermoset plastics, adhesives, and coatings, but not synthetic fibers (Plastics Europe, 2008; Proshad et al., 2018). Rochman et al. (2013) reported that the use of plastic products has increased rapidly, and 33 billion tons of plastic will likely be produced by 2050 . According to Europe-Plastics (2017) and Kaza et al. (2018), about 335 million tonnes (MT) of plastics were produced globally in 2016 and about 242 MT of plastic waste was generated in the same year.

Sheelanere et al. (2019) documented that plastics are grouped into two categories, thermoplastics and thermosets. Thermoplastics can be reheated, reshaped, frozen repeatedly and is widespread in everyday life. It is used in plastic shopping bags, cosmetic bottles, drinking bottles, C.D., food containers, toys and sport equipments (Proshad et al., 2018). Thermosets are with heat and pressure persistence and helps to maintain the form unchanged. They are used in electronic chips, fiber-reinforced composites, polymeric coatings, spectacle lenses, dental fillings etc. (Alabi et al., 2019; Wang et al., 2020). 
Based on constituents and type of material used for production, plastics are of different types like: Polyethylene Terephthalate (PET/PETE), High-density Polyethylene (HDPE), Polyvinyl Chloride (PVC), Lowdensity Polyethylene (LDPE), Polypropylene (PP), Polystyrene (PS) and Polycarbonate (PC)/Acrylonitrile Butadiene Styrene (ABS) (Proshad et al., 2018; Alabi et al., 2019; Chatterjee and Sharma, 2019; Sheelanere et al., 2019 and Wang et al., 2020). Other types of synthetic polymer includes Polyethylene (PE), Polyester (PES), Polyvinylidene Chloride (PVDC), High-impact Polystyrene (HIPS), Polyamides (PA), Polyurethanes (PU), Ureaformaldehyde (UF), Melamine formaldehyde (MF), Polymethyl methacrylate (PMMA), Polytetrafluoroethylene (PTFE) and Polylactic acid (PLA) etc. (Wang et al., 2020).

PET/PETE/Stomach plastic is clear, tough, solvent resistant, barrier to gas and moisture and softens at $80 \mathrm{C}$. It is used to make disposable water bottles, utensils, containers for juice, soft drinks, butter, salad dressing, vegetable oil, mouthwash, cosmetics, biscuit trays etc. It is prepared for 'one time use only' and is relatively safe (Proshad et al., 2018). HDPE is the most used plastic in the world and is heat-resistant. It is used to make milk containers, detergent bottles, refrigerators, toys, various types of plastic grocery bags, etc. HDPE is strong, irritable, heat-prone with no known health risk (Alabi et al., 2019).

PVC is heat-resistant, flexible, unobtrusive polymer and is used in plumbing pipes and guttering, siding, shower curtains, blood bags, window frames, and flooring. It contains toxic chemical substances such as Bisphenol A (BPA), thalates, lead, dioxin, crater and cadmium. Disposal of PVC causes marine pollution and severe health risk to cause cancer, birth defects, genetic changes, chronic bronchitis, ulcers, skin diseases, deafness, vision failure, indigestion and liver dysfunction (Chatterjee and Sharma, 2019). LDPE is heat-resistant, transparent and opaque, flexible and rigid but fragile polymer. It is used in packaging of frozen foods, preparation of juices and milk cartons. LDPE is also used in outdoor furniture, siding, wire cable, floor tiles, plastic bags, shower curtains, buckets, clamshell packaging, and soap dispenser bottles. LDPE do not contain any harmful components and its use is safe for food and beverages (Wang et al., 2020).

PP is strong, semi-transparent, high in heat and hydrophobic. PP is used for packing yogurt, medicine, beverage, ketchup etc. PP containers are not harmful and are considered safe for the human body and for food and beverages (Proshad et al., 2018). PS is a petroleum-based plastic and contains benzene, which is known carcinogen for the human body. PS is used in packaging and insulating materials. Styrene poses health risk and long-term exposure is neurotoxic and causes cytogenetic, carcinogenic and haematological effects (Alabi et al., 2019). PC has higher specific density and is used in baby bottles, reusable bottles and for packaging consumer goods. It is also used in CDs, DVDs, tail light on cars, hard plastic canteens, cigarette lighters etc. PC container is made of BPA which poses health risk. Due to health risk, polycarbonate plastic use is unsafe (Chatterjee and Sharma, 2019).

According to Derraik (2002), plastics make up most of the marine debris worldwide and identifies the principal sources as discarded or lost plastic fishing gear, garbage dumping at sea by vessels and land-based plastic litter from densely populated or industrialized 
areas. Cunningham (2003) studied that plastic debris find their entry into marine ecosystem by land (storm water, wind blow and beach users) and ocean (recreational, shipping and offshore petroleum rigs). Society has used the ocean as a convenient place to dispose of unwanted materials and waste products for many centuries, either directly or indirectly via rivers (GESAMP, 2015).

Threats of plastics to marine biota are mechanical due to ingestion and entanglement, by various species of seabirds, marine mammals and sea turtles (Derraik, 2002). It affects at least 267 species including $86 \%$ of sea turtles, $44 \%$ of seabirds and $43 \%$ of marine mammals (Isangedighi et al., 2018). Debris in oceans and seas is an aesthetic problem and can have severe impacts on marine organisms and habitats (Adane and Muleta, 2011; Hasnat and Rahman, 2018).

Improper management, lack of information about its negative effect, irresponsible use and dumping of plastic products turns this planet into "plastic planet". These plastic materials appeared as a great threat for human and animal health (Chatterjee and Sharma, 2019). Alabi et al. (2019) reviewed that indiscriminate disposal of wastes from plastics and plastic products can lead to environmental pollution with natural beauty deterioration, entanglement and death of aquatic organisms, sewage system blockage in towns and cities, create conducive environment for mosquitoes and other vectors and production of foul smells, reduction in water percolation and normal agricultural soils aeration.

Literature review reveals that barring few reports, no comprehensive report exists on marine debris with special reference to plastic polymer types from India and from Maharashtra in particular. In India, investigation on marine debris by Sridhar et al. (2007), Ghosh et al. (2013), Jayasiri et al. (2013), Sulochanan et al. (2013), Selukar et al. (2014), Kripa et al. (2016), Pawar et al. (2016), Veerasingam et al. (2016), Kaladharan et al. (2017), Mugilarasan et al. (2017), Panda et al. (2017), Dharmamony (2018), Chatterjee and Sharma (2019), Maharana et al. (2019), Nisanth and Kumar (2019), Sheelanere et al. (2019), Viswambharan et al. (2019), Das et al. (2020), Kapinga and Chung (2020), Kumar et al. (2020), Nagarajan et al. (2020), Veerasingam et al. (2020) and Sreelakshmi and Chitra (2021) are worth to mention here.

Plastic pollution of the oceans is a growing problem about which few details are known with any certainty. Inventorying and monitoring of plastic debris in marine ecosystem is one of the means to assess the magnitude of plastic accumulation and helps to mitigate possible measures to reduce the menace (Sridhar et al., 2007). Except studies on accumulation of plastic litter on high-water strandline of urban beaches in Mumbai by Jayasiri et al. (2013); no scientific documentation of the marine debris and marine pollution by plastic from Mumbai and Navi Mumbai is available.

Coastal environment of Panvel, Navi Mumbai has been under considerable stress since the ongoing construction of NaviMumbai International Airport (NMIA) by the City and Industrial Development Corporation (CIDCO). Construction of NMIA has resulted into habitat destruction and fragmentation, deforestation, encroachment, reclamation and urbanization in the study area. It has affected the livelihood of local fishermen and coastal community along with ecology of fauna from 
Panvel, Navi Mumbai (Pawar, 2013; Pawar et al., 2019, 2020, 2021). The present study was undertaken to report the baseline data of marine debris with special reference to plastic polymer type from the Panvel creek, Navi Mumbai, India. This study is the first of its kind to be undertaken for the Navi Mumbai region of Maharashtra.

\section{Materials and Methods}

\section{Study Area:}

Navi Mumbai is basically a satellite township on the west shore of Maharashtra. It was made in 1971 to be another urban township of Mumbai by Government of Maharashtra. As per Census India 2011, it had a population of $1,119,477$. Panvel is located in Raigad district of Maharashtra in Konkan region and is a node of Navi Mumbai city.

Geographically, Panvel (1859'19.61" N $73^{\circ} 06^{\prime} 36.47^{\prime \prime}$ E) is located on the Western Ghats range at an elevation of about $11 \mathrm{~m}$ above sea level and has a tropical climate with most months of the year are marked by significant rainfall (Fig. 1). The Panvel is the most populated city (population of 1,80,464; Census India 2011) in Raigad district in Maharashtra, India. Panvel is a highly populated city due to its closeness to Mumbai. It is located in the Mumbai Metropolitan Region on the banks of Panvel Creek. Kalundre river flows across the city in the south-west region and opens up into Panvel creek.

\section{Study Location:}

The Panvel creek (Lat 18 58' 26.895" $\mathrm{N}$ to

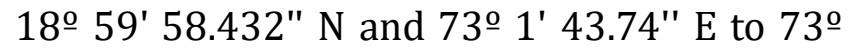
6' 48.269" E) is the tributary of Thane creek (Figs. 1, 2). The creek is $7 \mathrm{~km}$ long and is also called as Ulve creek. It passes through Taloja,
Panvel and Ulve, before entering the sea at Belapur. The creek is tide-dominated and the tides are semi-diuranal. The flood period lasts for about 6-7 $\mathrm{h}$ and the ebb period lasts for about $5 \mathrm{~h}$. The average annual precipitation is about $3267 \mathrm{~mm}$ of which about $80 \%$ is received during July to September. The temperature range is $12-36 \mathrm{C}$, whereas the relative humidity remains between $61 \%$ and $86 \%$ and is highest in the month of August. Panvel creek is characterized by extensive mud flats with sparse mangrove vegetation and less rocky stretches. Major area of the creek is dominated by the marshy areas and mud flats. The creek is resourceful with fin fish and shell fish fishery potential (Pawar et al., 2019).

For the present study, three sampling sites (Karanjade, Koliwada and site near ongoing Navi Mumbai International Airport), separated approximately by $2 \mathrm{~km}$ were selected. These sites were selected on the basis of their strategic locations and different anthropogenic activities along the entire coastal area.

Field study/Sampling:

Selected sites with a high density of plastic debris, were visited monthly from May 2020 to April 2021 for assessment of marine debris and polymer type of plastic during spring low tide and high tide. Plastic debris was collected from observations with naked eyes and were photographed using Cannon 1100 D Zoom camera (Fig. 3). Approximately $50 \mathrm{~kg}$ of marine debris was collected from each sampling site and was sorted into a nonplastic debris and plastic debris. Plastic debris was assessed for \% composition of plastic as per type of polymer and further categorized according to plastic code, acronym, full name 


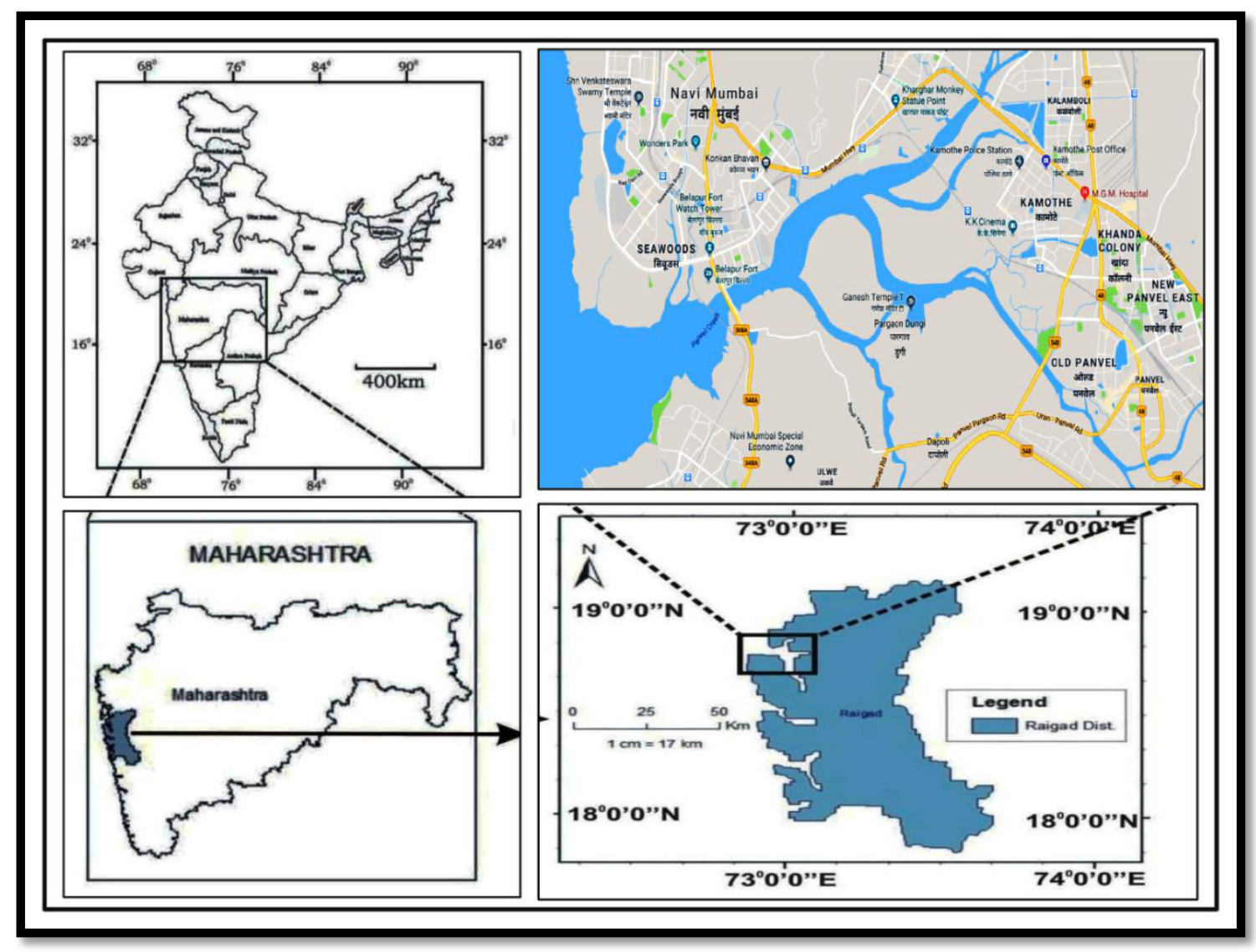

Fig. 1: Location map of study area representing Panvel creek.

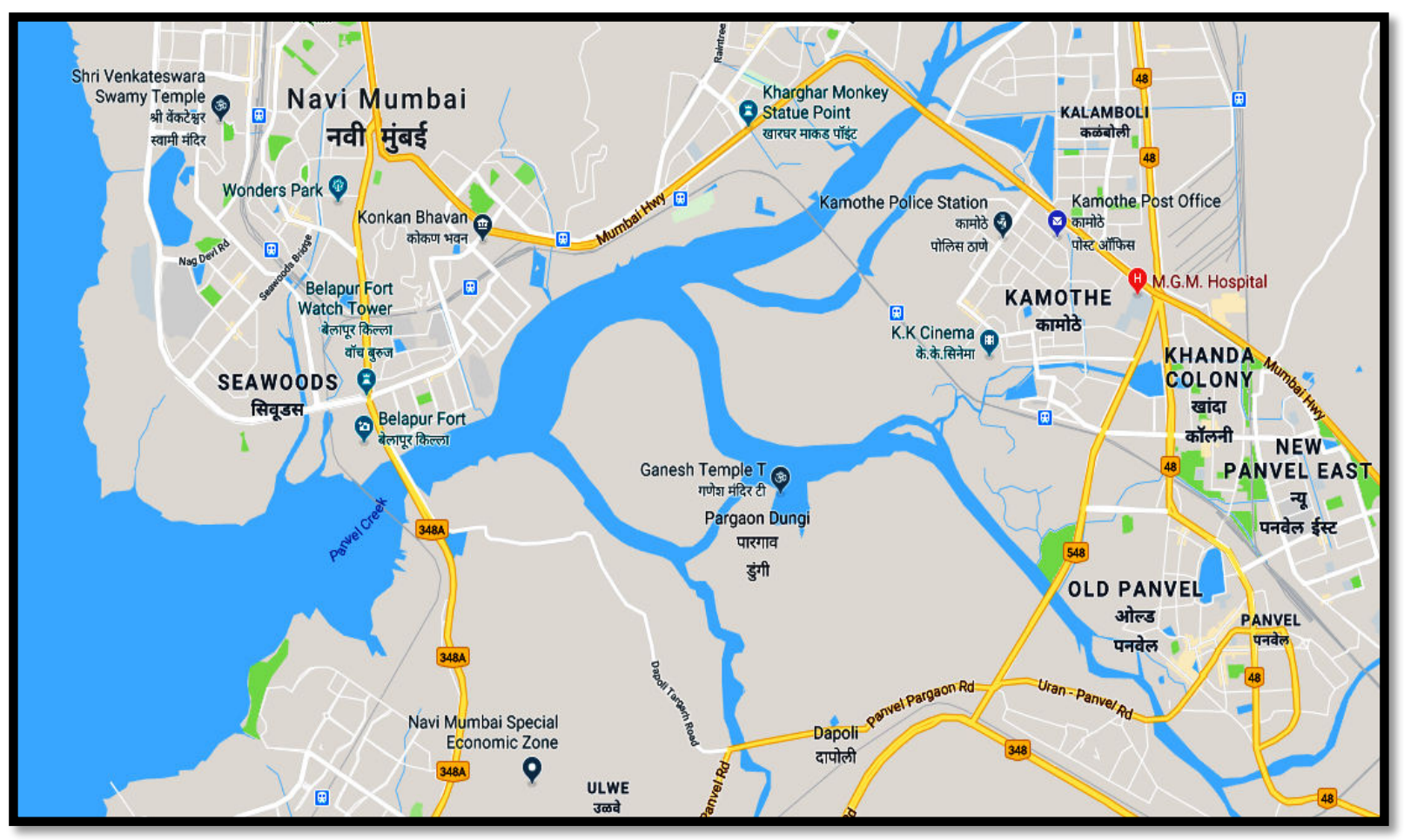

Fig. 2: Tributaries of Panvel creek (Source: Google Map). 
and common examples collected following the work of Pawar et al. (2016) and Sheelanere et al. (2019).

\section{Results and Discussion}

During the present study, marine debris other than plastic consisting of 8 different types representing 38 items was observed. Recorded items consist of mainly consumer and manufactured items represented by glass and plastic bottles, cans, bags, rubber, metal, fibreglass, cigarettes, fishing gears etc. Number of items recorded in each type reveals that 11 items belongs to fruits and vegetables, 7 each to metals and others, 4 to wood, 3 each to glass and rubber, 2 to cotton and 1 to leather. Among non-plastic marine debris, maximum \% composition (28.94\%) of fruits and vegetable and minimum (2.63\%) of leather was recorded (Tables 1, 3; Fig. 4).

Among plastic debris, 8 different types of polymers representing 65 items were observed. Types of recorded polymers consist of Polyethylene terephthalate (PETE/PET), High density polyethylene (HDPE), Polyvinyl chloride (PVC), Low density polyethylene (LDPE), Polypropylene (PE), Polystyrene (PS), Polyamide/Nylon, Acrylonitrile Butadiene Styrene (ABS) and Polyurethane (PU).

Number of items recorded in each polymer type reveals that 13 items belong to plastic code 2:HDPE, 12 to $3: \mathrm{PVC}, 11$ to 5:PP, 9 to 6:PS, 8 to 4:LDPE, 6 to 1: PETE/PET and 3 each to 7: PA and other and 8:PU, respectively. Maximum \% composition (20.00\%) of 2:HDPE and minimum (4.61\%) of 7: PA and other and 8:PU, respectively was recorded (Tables 2,4 ; Fig. 4).

Maximum per cent composition of fruits and vegetables recorded in the present study is attributed to the disposal of domestic wastes into the creek by the local population as majority of fishermen community of Panvel Koliwada is inhabiting in the vicinity of the creek. High content of metals (Beer tin, Metal rods, Lid of Metal containers, Fry Pan, Bangles, Tin Cover, Umbrella) in marine debris is correlated to the disposal of scrap materials from the fishing crafts into the creek and also to the domestic wastes released intentionally or un-intentionally into the creek. Results of the present study are in agreement with Doyle et al. (2011) in coastal pelagic ecosystems of the Northeast Pacific ocean.

Higher density of HDPE (Derelict fishing nets, Lid of plastic container, Plastic thermos, Shampoo bottle, Crushed plastic container, Travel case, Vicks Vaporub bottle, Rexene travel bag, Face wash tube, Large containers, Ponds Face Powder bottle, Colgate Tooth Paste tube, Harpic Toilet Cleaner bottle lid) is attributed to the wastes released from the fishing vessels and also to the domestic and municipal wastes. Similar results were reported by Sridhar et al (2007) along the Beaches of Karnataka, Southwest Coast of India, Adane and Muleta (2011) in Jimma City, Southwestern Ethiopia and Erni-Cassola et al (2019) regarding the distribution of plastic polymer types in the marine environment.

The present study indicate that the higher proportion of harmful plastic polymers, PVC $(18 \%)$ and PS (14\%) is a point of concern (Fig. 5). As a result, health of marine biota and human faces a health risk due to the toxic effects of plastic. Proshad et al. (2018) stated that PVC contains many toxic chemical substances (BPA, thalates, led, dioxin, crater, and cadmium) which can cause cancer, birth defects, genetic changes, chronic bronchitis, ulcers, skin diseases, deafness, vision failure, 

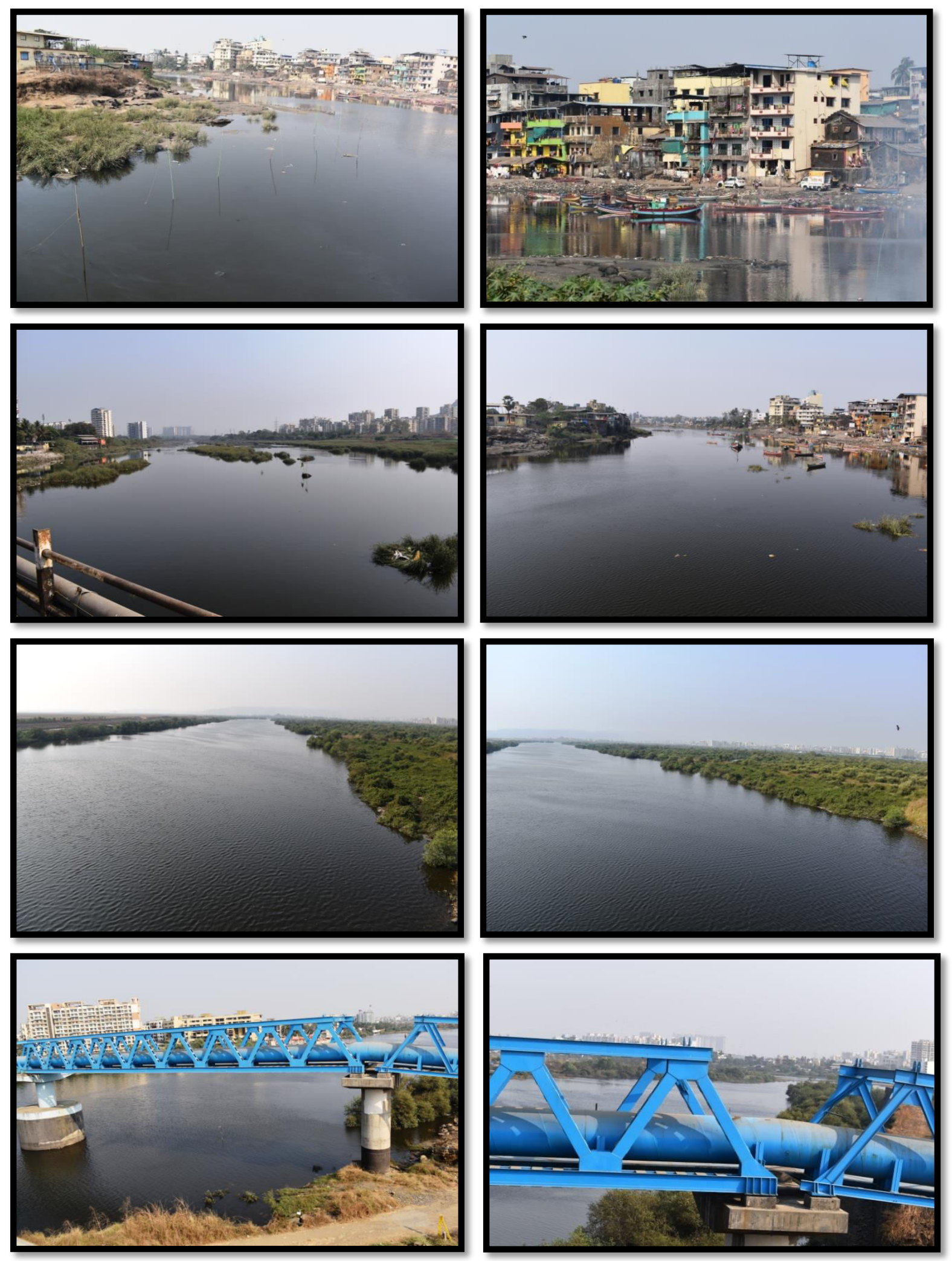

Fig. 3: Study area representing sampling sites along Panvel creek. 

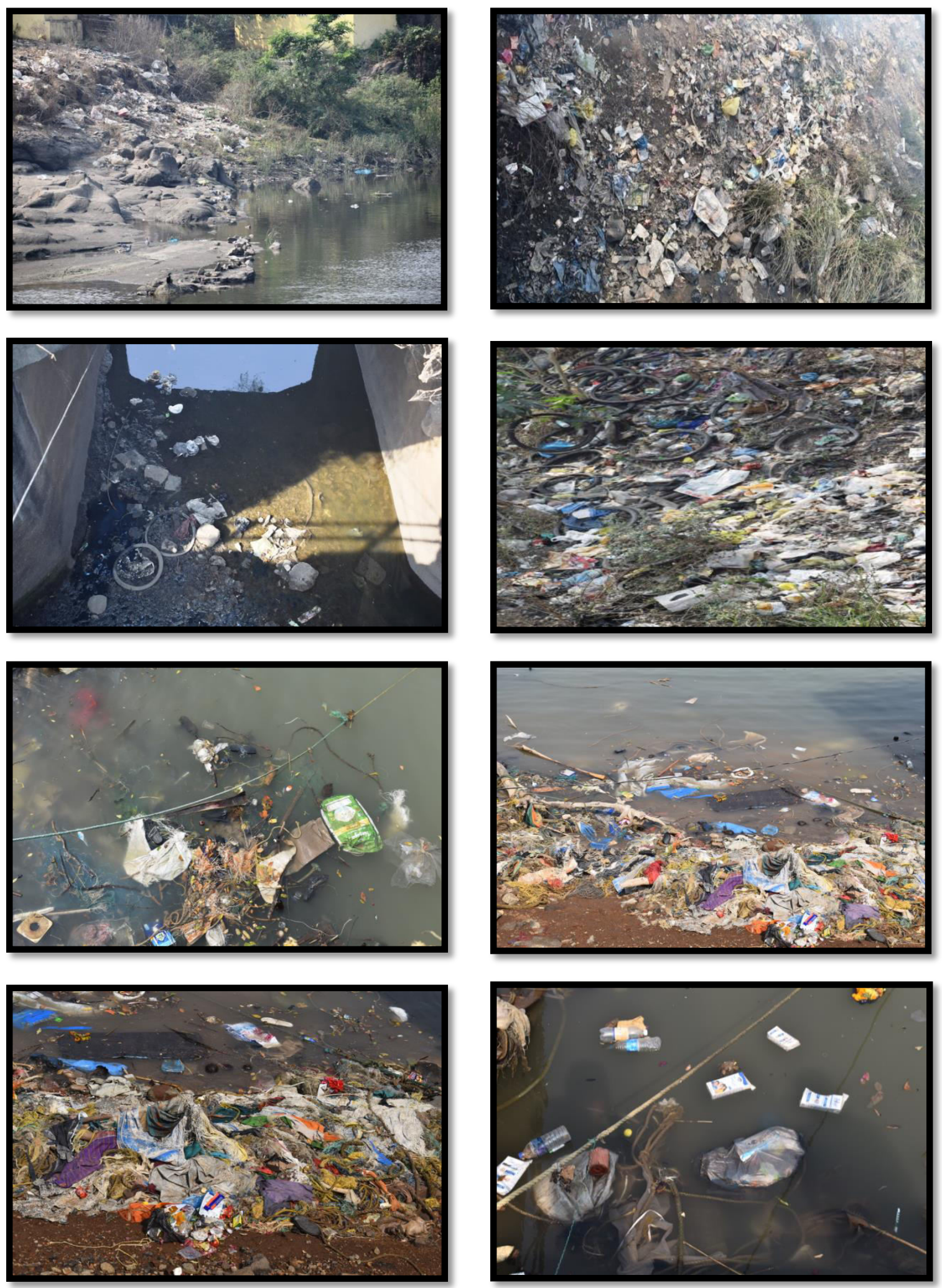

Fig. 4: Plastic marine debris recorded at Panvel creek. 
Table 1: Types of marine debris other than plastic recorded at Panvel creek

\begin{tabular}{|c|c|c|}
\hline S. No. & Type & Items recorded \\
\hline 1 & Glass & Beverage bottles, Glass bulb, Fluorescence tube light \\
\hline 2 & Wood & Wooden pieces, Processed timber, Painting brush, Wooden box \\
\hline 3 & Rubber & Hand gloves, Tyres (Car, Bicycle), Sheets \\
\hline 4 & Cotton & Clothing, Jerkin \\
\hline 5 & Metal & $\begin{array}{l}\text { Beer tin, Metal rods, Lid of Metal containers, Fry Pan, Bangles, Tin Cover, } \\
\text { Umbrella }\end{array}$ \\
\hline 6 & Leather & Leather belt \\
\hline 7 & $\begin{array}{l}\text { Fruits and } \\
\text { Vegetables }\end{array}$ & $\begin{array}{l}\text { Pineapple, Lemon, Coconut, Onion, Garlic, Potato, Sweet Pea, Brinjal, Chilli, } \\
\text { Banana Peels, Tomatos }\end{array}$ \\
\hline 8 & Other & $\begin{array}{l}\text { Dead body of Dog, Flowers, Paper, Egg shells, Chutney Packet of Chinese } \\
\text { food, Broom, Jaw bone with teeth - Goat }\end{array}$ \\
\hline
\end{tabular}

Table 2: Some common types of Plastic wastes recorded at Panvel creek.

\begin{tabular}{|c|l|l|l|}
\hline $\begin{array}{c}\text { Plastic } \\
\text { code }\end{array}$ & Acronym & \multicolumn{1}{|c|}{ Full name } & \multicolumn{1}{c|}{ Items recorded } \\
\hline 1 & PETE/PET & $\begin{array}{l}\text { Polyethylene } \\
\text { terephthalate }\end{array}$ & $\begin{array}{l}\text { Thick plastic bottle, Real fruit juice container, Small juice bottle, } \\
\text { Sanitizer plastic bottle, Cigarette paper rapper, Plastic colour bottle }\end{array}$ \\
\hline 2 & HDPE & $\begin{array}{l}\text { High density } \\
\text { polyethylene }\end{array}$ & $\begin{array}{l}\text { Derelict fishing nets, Lid of plastic container, Plastic thermos, Shampoo } \\
\text { bottle, Crushed plastic container, Travel case, Vicks Vaporub bottle, } \\
\text { Rexene travel bag, } \\
\text { Face wash tube, Large containers, Ponds Face Powder bottle, Colgate } \\
\text { Tooth Paste tube, Harpic Toilet Cleaner bottle lid }\end{array}$ \\
\hline 3 & PVC & Polyvinyl chloride & $\begin{array}{l}\text { Nylon rope, Food containers, Foot wares, } \\
\text { Tyre of Children 3-wheeler bicycle, Gutkha and Candy wrappers, } \\
\text { Medicine tablet strip, Lime tube, Baby milk feeding bottle, Whistle, } \\
\text { Comfort Mosquito Repellent Agarbatti wrapper, Measuring Tape }\end{array}$ \\
\hline 4 & LDPE & $\begin{array}{l}\text { Low density } \\
\text { polyethylene }\end{array}$ & $\begin{array}{l}\text { Sanitary napkin wrapper, Carry bags, Milk bag, Hand wash refill pack, } \\
\text { Belt of School bag, Toys, Appay Tetra Pack, Ointment Tube }\end{array}$ \\
\hline 5 & PP & Polypropylene & $\begin{array}{l}\text { Junk food wrappers, Cement bags, Biscuit wrappers, Basmati rice bag, } \\
\text { Kinder joy ice cream container, } \\
\text { Bread wrapper, Plastic bottle lid, Car mirror socket, Ice cream } \\
\text { container, Broom handle, Surgical Mask }\end{array}$ \\
\hline 6 & PS & Polystyrene & $\begin{array}{l}\text { Thermocol, Disposable Tea cups, Sketch pen, } \\
\text { Disposable spoons, Disposable glass, Ball pen, Floaters, Ring, Sponge } \\
\text { sheet for bottle }\end{array}$ \\
\hline 7 & PC & Polycarbonate & ----- \\
\hline & PA & Polyamide/Nylon & Toothbrush \\
\hline & Other & $\begin{array}{l}\text { Acrylonitrile } \\
\text { Butadiene Styrene } \\
\text { ABS) }\end{array}$ & Milk bottle lid, Thermometer \\
\hline & PU & Polyurethane & Plastic footwear, Condom, Foam Net \\
\hline & & &
\end{tabular}




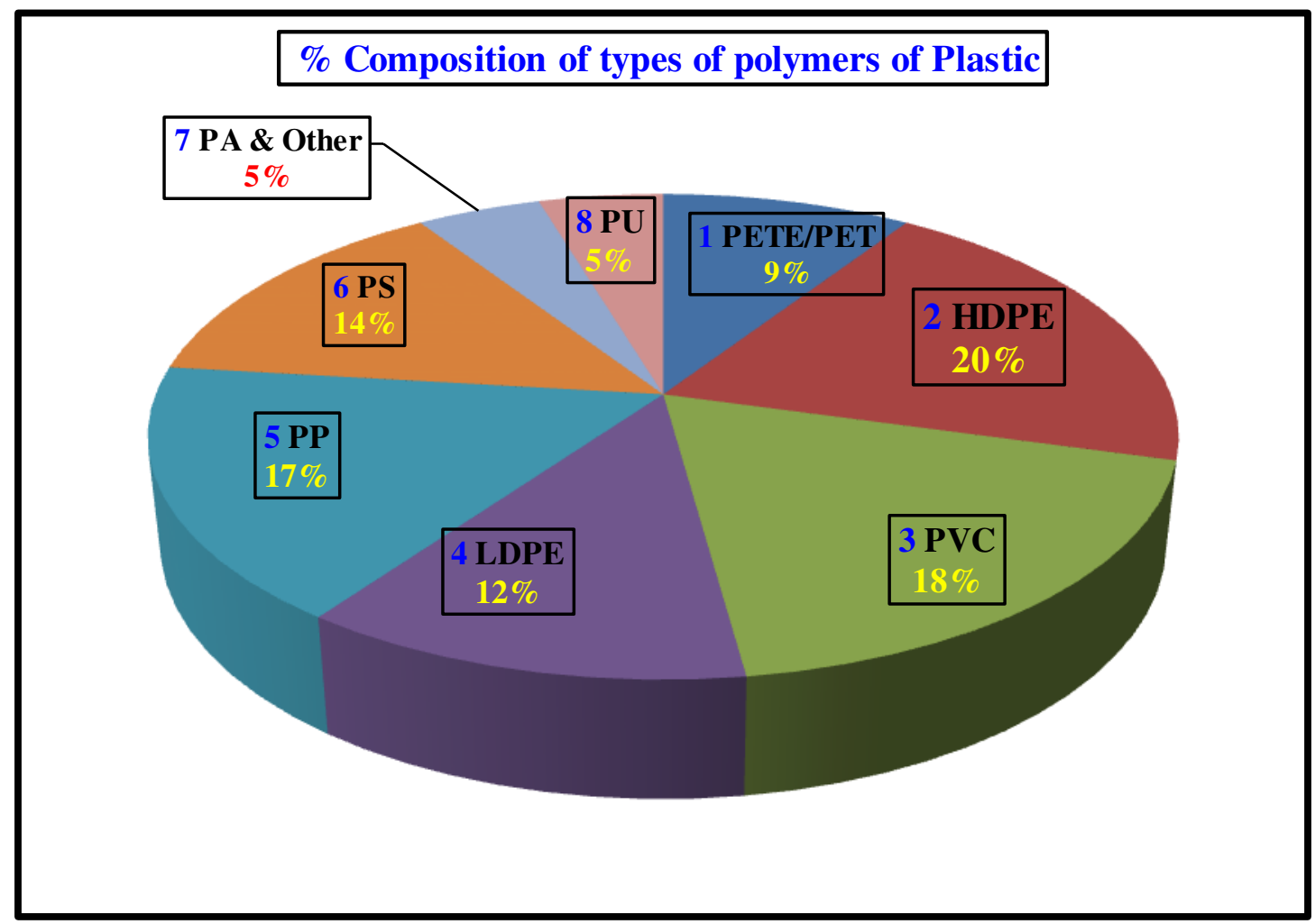

Fig. 5: Per cent composition of polymer types of plastic recorded at Panvel creek.

Table 3: Per cent composition of marine debris other than plastic from Panvel creek

\begin{tabular}{|c|c|c|c|}
\hline S. No. & Type of marine debris & $\begin{array}{c}\text { Items } \\
\text { recorded }\end{array}$ & $\begin{array}{c}\text { \% } \\
\text { Composition }\end{array}$ \\
\hline 1 & Glass & 3 & 7.89 \\
\hline 2 & Wood & 4 & 10.52 \\
\hline 3 & Rubber & 2 & 7.89 \\
\hline 4 & Cotton & 7 & 5.26 \\
\hline 5 & Metal & 1 & 18.42 \\
\hline 6 & Leather & 11 & 28.94 \\
\hline 7 & Fruits and Vegetables & 7 & 18.42 \\
\hline 8 & Other & $\mathbf{3 8}$ & $\mathbf{1 0 0}$ \\
\hline & Total & & \\
\hline
\end{tabular}


Table 4: Per cent composition of type of polymer of plastic from Panvel creek

\begin{tabular}{|c|c|l|c|c|}
\hline $\begin{array}{c}\text { Plastic } \\
\text { code }\end{array}$ & Acronym & \multicolumn{1}{|c|}{ Full name } & Items recorded & $\begin{array}{c}\text { \% } \\
\text { Composition }\end{array}$ \\
\hline 1 & PETE/PET & Polyethylene terephthalate & 6 & 9.23 \\
\hline 2 & HDPE & High density polyethylene & 13 & 20.00 \\
\hline 3 & PVC & Polyvinyl chloride & 12 & 18.46 \\
\hline 4 & LDPE & Low density polyethylene & 8 & 12.30 \\
\hline 5 & PP & Polypropylene & 11 & 16.92 \\
\hline 6 & PS & Polystyrene & 9 & 13.84 \\
\hline 7 & PA and & Polyamide/Nylon, & 3 & 4.61 \\
\hline 8 & Other & Acrylonitrile Butadiene Styrene $(\mathrm{ABS}$ & & \\
\hline Total & & Polyurethane & 3 & 4.61 \\
\hline
\end{tabular}

indigestion, and liver dysfunction. Reports of Alabi et al. (2019) showed that long exposure to styrene can cause neurotoxic, hematological, cytogenetic and carcinogenic effects.

Along Panvel creek, food-based plastic debris and domestic wastes (fruits and vegetables) were dominant. This indicates the anthropogenic pressure and the input due to human activities. Such plastic debris can increase the risk of biomagnification of hydrophobic compounds like polychlorinated biphenyls (PCBs) and DDT, which will upset the balance of the fragile coastal ecosystem (Dharani, 2003; Sridhar et al. 2007). Results of the present investigation are in agreement with the work of Gregory (2009), Stephanie et al. (2013), Panda et al. (2017), Mugilarasan et al. (2017), Chatterjee and Sharma (2019), Nisanth and Kumar (2019) and Kumar et al. (2020).

This study shows that, at present the Panvel creek is moderately polluted with marine debris with special reference to plastic which reduces the aesthetic and the recreational value of the creek. It also affects the coastal diversity and reduces marine resources. Since no earlier reports are available, data presented here can be taken as a baseline data on marine debris and percentage composition and types of polymers of plastic from Panvel creek, Navi Mumbai, India.

\section{Conclusion}

It can be concluded that the Panvel creek is moderately polluted with marine debris particularly plastic, which reduces the aesthetic and the recreational value of the creek. Concerns are expressed about economic losses and health issues of the local coastal community. 3R (Reduce, reuse and recycling) is the current solution to the overuse of plastics. 'Thinking globally and acting locally' is a fundamental attitude to reduce such an environmental threat.

\section{Acknowledgement}

Encouragement and support provided by Ganesh A. Thakur, Principal, Mahatma Phule Arts, Science and Commerce College, Panvel, Raigad, Navi Mumbai, India is gratefully acknowledged. Authors are thankful to the 
Head, Department of Zoology for providing necessary facilities for the present study.

\section{References}

Adane Legesse and Diriba M. (2011) Survey on the usage of plastic bags, their disposal and adverse impacts on environment: A case study in Jimma City, Southwestern Ethiopia. J Toxicol Environ Hlth Sci. 3(8): 234-248.

Alabi OA, Ologbonjaye KI, Awosolu O and Alalade OE. (2019) Public and environmental health effects of plastic wastes disposal: A review. J Toxicol Risk Assess. 5: 021. doi.org/10.23937/2572-4061.1510 021.

Allsopp M, Walters A, Santillo D and Johnston P. (2009) Plastic debris in the World's Oceans. Green Peace International, Amsterdam, Netherlands, pp. 44.

Andrady AL and Neal MA. (2009) Applications and societal benefits of plastics. Philos Trans R Soc Lond B Biol Sci. 364: 1977-1984.

Barnes KA, Galagari F, Thompson RC and Barlaz M. (2009) Accumulation and fragmentation of plastics debris in global environment. Philos Trans R Soc Lond B Biol Sci. 364: 1985-1998.

Brander SM, Fontana RE, Mata TM, Gravem SA, Hettinger A, Bean JR, Szoboszlai AI, Keiper CA. and Marrero ME. (2011) The ecotoxicology of plastic marine debris. Am Biol Teacher 73(8): 474-478.

CBD Technical Series No. 83. (2016) Marine debris: Understanding, preventing and mitigating the significant adverse impacts on marine and coastal biodiversity. Technical Series No.83. Secretariat of the Convention on Biological Diversity, Montreal, p. 78.

Chatterjee S and Shivika S. (2019). Microplastics in our oceans and marine health. Field Actions Science Reports, Special Issue 19: 54-61. http://journals. openedition.org/factsreports/5257.

Cunningham DJ and Wilson SP. (2003) Marine debris on beaches of the greater Sydney region. J Coastal Res. 19: 421-430.

Das S, Prabhakar J and Chatterjee A. (2020). Assessing marine plastic pollution in India. IEG Working Paper No. 389, pp. 27.

Derraik JGB. (2002) The pollution of the marine environment by plastic debris: a review. Mar Poll Bull. 44: 842-852.

Dharani G, Nazar AKA, Ventakesan R and Ravindran M. (2003) Marine debris in Great Nicobar. Current Sci. 85: 574-575.
Dharmamony V. (2018) Plastics in the Oceans: Throttling Marine Life. Science Reporter, June 2018: 23-29.

Doyle MJ, William W, Noelle MB and Seba BS. (2011) Plastic particles in coastal pelagic ecosystems of the Northeast Pacific ocean. Mar Environ Res. 71: 41e52. doi:10.1016/j.marenvres.2010.10.001.

Erni-Cassola G, Vinko Z, Matthew IG and Joseph AC. (2019) Distribution of plastic polymer types in the marine environment; A metaanalysis. J Hazard Mat. 369: 691-698.

Europe-Plastics (2017) An analysis of European plastics production, demand and waste data. The Association of Plastics Manufacturers in Europe and the European Association of Plastics Recycling and Recovery Organisations and Plastics Europe's Market Research and Statistics Group.

GESAMP. (2015) Sources, fate and effects of microplastics in the marine environment: a global assessment (ed.) Kershaw P.J. (IMO/FAO/UNESCOIOC/UNIDO/WMO/IAEA/UN/UNEP/UNDP Joint Group of Experts on the Scientific Aspects of Marine Environmental Protection). Rep. Stud. GESAMP No. 90. pp. 96.

Ghosh SK, Pal S and Ray S. (2013) Study of microbes having potentiality for biodegradation of plastics. Environ Sci Poll Res Int. 20: 4339-4355.

Gregory MR. (2009) Environmental implications of plastic debris in marine settings--entanglement, ingestion, smothering, hangers-on, hitch-hiking and alien invasions. Philos Trans R Soc Lond B Biol Sci. 364: 2013-2025.

Hasnat MA and Mohammad AR. (2018) A review paper on the hazardous effect of plastic debris on marine biodiversity with some possible remedies. Asian J Med Biol Res. 4(3): 233-241.

Isangedighi AI, Gift Samuel D and Ofonmbuk IO. (2018). Plastic waste in the aquatic environment: Impacts and management. Environ. 2:1-31.

Jambeck JR, Geyer R, Wilcox C, Siegler TR, Perryman M, Andrady A, Narayan R and Law KL. (2015) Plastic waste inputs from land into the ocean. Science 347 : 768 - 771.

Jayasiri HB, Purushothaman CS and Vennila A. (2013) Plastic litter accumulation on high-water strandline of urban beaches in Mumbai, India. Environ Monit Assess. 185:7709-7719.

Kaladharan P, Vijayakumaran K, Singh VV, Prema D, Asha PS, Sulochanan B, Hemasankari P, Loveson Edward L, Shelton P, Veena S, Anasukoya A and Bhint HM. (2017) Prevalence of marine litter along the 
Indian beaches : A preliminary account on its status and composition. J Mar Biol Ass India 59 (1): 19-24.

Kapinga CP and Shing Hin C. (2020) Marine plastic pollution in South Asia. South and South-West Asia Development Papers 20-02, May 2020, pp. 52.

Kaza S, Lisa Y, Perinaz BT and Frank VW. (2018). What a waste 2.0 A global snapshot of solid waste management to 2050. Urban Development Series. World Bank Group. https://openknowledge. worldbank.org/bitstream/handle/10986/30317/2 11329ov.

Kripa V, Kaladharan P, Prema D, Jeyabaskaran R, Anil Kumar PS, Shylaja G, Sajikumar KK, Anasu Koya A, Preetha GN, Abhilash KS, Dhanya AM, John B, Ambrose TV, Divya ND, Vishnu PG and Jishnu M. (2016) A national marine debris management strategy to conserve marine ecosystems. Mar Fish Infor Serv T and E Ser., No. 228.

Kumar S, Mridula R, Rajesh K, Suyani N and Ahamed RA. (2020) Impact of microplastics on aquatic organisms and human health: A review. Int J Environ Sci Nat Res. 26(2): 556185.

Li WC, Tse HF and Fok L. (2016) Plastic waste in the marine environment: A review of sources, occurrence and effects. Sci Total Environ. 566-567: 333-349.

Lusher AL, Tirelli V, O'Connor I and Officer R. (2015) Microplastics in Arctic polar waters: the first reported values of particles in surface and subsurface samples. Sci Rep. 5: 14947.

Maharana D, Saha M, Dar JY, Rathore C, Sreepada RA, Xu XR, Koongolla JB and Li HX. (2019) Assessment of plastics along the west coast of India: Abundance, distribution, polymer type and toxicity. Chemosphere 246: 125708. doi:10.1016/j. chemosphere.2019.125708.

Moora H and Evelin P. (2016) Sources and pathways of marine litter. Stockholm Environment Institute Tallinn Centre (SEI Tallinn), BLASTIC, background Report, WP2 Mapping marine plastic litter sources, flows and pathways, pp 22.

Mugilarasan M, Venkatachalapathy R, Sharmila Nand Gurumoorthi K. (2017) Occurrence of microplastic resin pellets from Chennai and Tinnakkara Island: Towards the establishment of background level for plastic pollution. Indian J Geo Mar Sci. 46(06): 1210-1212.

Nagarajan VM, Kannappan PG, Aakriti K, Neha R and Krishnan A. (2020) A critical review on various trophic transfer routes of microplastics in the context of the Indian coastal ecosystem. Watershed Eco Environ. 2: 25-41.
National Oceanic and Atmospheric Administration (NOAA). (2010) Information on Marine Debris. <http://marinedebris.noaa.gov/info/welcome.html.

Nisanth HP and Biju KA. (2019) Observations on the entanglement of plastic debris in seabirds of the family Laridae along Kerala coast, India. J Aquat Biol Fish. 7: 115-119.

Panda A, Mohanty B and Jena AK. (2017) Coastal Pollution in India. Aqua Star. Article 6, March 2017: 1-6.

Pawar Prabhakar R. (2013) Monitoring of impact of anthropogenic inputs on water quality of mangrove ecosystem of Uran, Navi Mumbai, west coast of India. Mar Poll Bull. 75: 291-300.

Pawar Prabhakar R, Pore AJ, Rokade AG, Pawar NB and Patil SR. (2019) Monitoring of anthropogenic threats to mangrove ecosystem of Panvel creek, Navi Mumbai, India. Res Chron, VII (VII): 74-84.

Pawar Prabhakar R, Mhatre RP and Supnekar SS. (2021) Preliminary survey of major insect pests of rice (Oryza sativa L.) from Panvel, Navi Mumbai, India. Intern J Zool Invest. 7(1): 22-31.

Pawar Prabhakar R, Rokade AG, Supnekar SP, Meshram LN and Pawar NB. (2020) Anthropogenic impact on species diversity and distribution of birds from coastal region of Panvel, Navi Mumbai, India. Intern J Zool Invest. 6(2): 260-271.

Pawar Prabhakar R, Shirgaonkar SS and Patil RB. (2016) Plastic marine debris: Sources, distribution and impacts on coastal and ocean biodiversity. PENCIL Pub Biol Sci. (Oceanography) 3(1): 40-54.

Plastics Europe. (2008) The compelling facts about Plastics 2007: an analysis of plastics production, demand and recovery for 2007 in Europe. Brussels, Belgium: Plastics Europe.

Proshad R, Kormoker T, Saiful IM, Mohammad AH, Mahfuzur RM and Mahabubur RMM. (2018) Toxic effects of plastic on human health and environment: A consequences of health risk assessment in Bangladesh. Intern J Hlth. 6(1): 1-5.

Rochman CM, Browne MA, Halpern BS, Hentschel BT, Hoh E, Karapanagioti HK, Rios-Mendoza LM, Takada H, Teh S and Thompson RC. (2013) Policy: Classify plastic waste as hazardous. Nature 494:169-171.

Ryan PG. (2015) A brief history of marine litter research. Marine Anthropogenic Litter (eds.) Bergmann M., Gutow L. and Klages M., Dordrecht: Springer, pp: 1-25.

Schwarz AE, Ligthart TN, Boukris E and Harmelen van T. (2019) Sources, transport, and accumulation of different types of plastic litter in aquatic 
environments: A review study. Mar Poll Bull. 143: 92-100.

Selukar NB, Chaitanya VL and Chetankumar GI. (2014) Waste thermocol to adhesive for better environment. Int J Innov Res Adv Eng. 1(6): 98-100.

Sheelanere P, Kumar R, Kumar S, Julian J, Latheef A, Raghunathan N, Vivekanandan V and Chakraborty S. (2019) Reducing ocean plastics-formative research leading to intervention planning in India. Research Report. Natural Resources Institute, University of Greenwich, Central Avenue, Chatham Maritime, Kent, ME4 4TB. UK, pp. 70.

Sreelakhmi T and Chitra KC. (2021) Microplastics contamination in the environment: An ecotoxicological concern. Intern J Zool Invest. 7(1): 230-258.

Sridhar KR, Deviprasad B, Kamchand KS and Bhat R. (2007) Plastic debris along the beaches of Karnataka, Southwest Coast of India. Asian J Water Environ Poll. 6(2): 87-93.

Stephanie L, Wright R, Thompson C and Tamara SG. (2013) The physical impacts of microplastics on marine organisms: A review. Environ Poll. 178: 483e492. http://dx.doi.org/10.1016/j.envpol. 2013. 02.031

Sulochanan B, Lavanya S and Kemparaju S. (2013) Influence of river discharge on deposition of marine litter. Mar Fish Inform Ser T and E Ser., No. 216.
Thompson RC, Moore CJ, VomSaal FS and Swan SH. (2009) Plastics, the environment and human health: Current consensus and future trends. Philos Trans R. Soc Lond B Biol Sci. 364(1526): 2153-2166.

Veerasingam S, Ranjani M, Venkatachalapathy R, Bagaev A, Mukhanov V, Litvinyuk D, Verzhevskaia L, Guganathan L and Vethamony P. (2020) Microplastics in different environmental compartments in India: Analytical methods, distribution, associated contaminants and research needs. Trends Anall Chem. 133: 116071. doi.org/ 10.1016/j.trac.2020.116071.

Veerasingam S, Mahua S, Suneel V, Vethamony P, Andrea CR, Bhattacharyya S and Naik BG. (2016) Characteristics, seasonal distribution and surface degradation features of microplastic pellets along the Goa coast, India. Chemosphere 159: 496-505.

Viswambharan D, Prathibha R, Geetha S, Sujitha T, Joshi KK, Latha S and Jaiswar AK. (2019) Occurrence and abundance of plastic particles in razor moonfish along the eastern Arabian Sea. J Mar Biol Ass India 61(2): 27-33.

Wang Yung-Li, Yu-Hsuan L, I-Jen Chiu, Yuh-Feng L and Hui-Wen C. (2020) Potent impact of plastic nanomaterials and micromaterials on the food chain and human health. Int J Mol Sci. 21: 1727.

Worm B, Heike KL, Isabelle J, Chris $\mathrm{W}$ and Jenna J. (2017) Plastic as a persistent marine pollutant. Ann Rev Environ Resour. 42: 1-26. 